\title{
History of innate immunity in neurodegenerative disorders
}

\section{Patrick L. McGeer* and Edith G. McGeer}

Kinsmen Laboratory of Neurological Research, University of British Columbia, Vancouver, BC, Canada

\section{Edited by:}

Roger A. Barker, University of Cambridge and Addenbrooke' Hospital, UK

Reviewed by:

Jason B. Wu, Cedars-Sinai Medical Center, USA

Muzamil Ahmad, Indian Institute of Integrative Medicine, India

*Correspondence:

Patrick L. McGeer, Kinsmen Laboratory of Neurological Research, University of British Columbia, 2255 Wesbrook Mall, Vancouver, BC,

Canada V6T1Z3.

e-mail: mcgeerpl@interchange.ubc.ca
The foundations of innate immunity in neurodegenerative disorders were first laid by Del Rio Hortega (1919). He identified and named microglia, recognizing them as cells of mesodermal origin. Van Furth in 1969 elaborated the monocyte phagocytic system with microglia as the brain representatives. Validation of these concepts did not occur until 1987 when HLADR was identified on activated microglia in a spectrum of neurological disorders. HLA-DR had already been established as a definitive marker of immunocompetent cells of mesodermal origin. It was soon determined that the observed inflammatory reaction was an innate immune response. A rapid expansion of the field took place as other markers of an innate immune response were found that were made by neurons, astrocytes, oligodendroglia, and endothelial cells. The molecules included complement proteins and their regulators, inflammatory cytokines, chemokines, acute phase reactants, prostaglandins, proteases, protease inhibitors, coagulation factors, fibrinolytic factors, anaphylatoxins, integrins, free radical generators, and other unidentified neurotoxins. The Nimmerjahn movies demonstrated that resting microglia were constantly active, sampling the surround, and responding rapidly to brain damage. Ways of reducing the neurotoxic innate immune response and stimulating a healing response continue to be sought as a means for ameliorating the pathology in a spectrum of chronic degenerative disorders.

Keywords: HLA-DR, Alzheimer disease, Parkinson disease, complement, neuroinflammation

\section{BACKGROUND}

Pio Del Rio Hortega, one of the greatest of all neuroscientists, established the basic foundation of neuroinflammation with his classic 1919 paper "El tercer elemento de los centros nerviosis" (Del Rio Hortega, 1919). He had developed an ammoniacal silver carbonate modification of the Golgi technique. With this new method he was able to identify small spidery cells which he named microglia. He recognized that they were of mesodermal origin, and that they migrated to the brain in late embryonic life. He also recognized their phagocytic capacity by examining their reaction to stab wounds. He categorized their morphology as resting, ameboid, and reactive. By further modifying his technique, he later recognized another type of glial cell which was of epithelial origin and had a sparse cytoplasm. He named these cells oligodendroglia, perhaps because of the difficulty he encountered in staining them.

These two glial cell types made up "the third element" which had baffled Ramon y Cajal. Cajal, Hortega's mentor and employer, had clearly identified astrocytes with his methodology, and knew there were still unclassified glial cells. He thought the cells identified by Hortega might be another astrocytic type that was resistant to staining. He objected to Hortega's desire to publish his results on oligodendroglia, and when Hortega went ahead, believing others would make the same discovery, Cajal dismissed him. Hortega's own account of these travails, which he never published, were obtained after his death, later appearing in part in Haymaker and Adams treatise on the histopathology of the nervous system (Haymaker and Adams, 1980a, pp. 484-485).

Hortega's travails were not limited to his falling out with Cajal. The Madrid laboratory he had set up after his departure from Cajal was bombed out in the Spanish civil war. He moved for a time to
Paris, and then to Oxford, but was uncomfortable in these locations. As a Spaniard opposed to Franco, he emigrated to Buenos Aires in 1938 where, in 1945, he died of cancer.

His findings and their interpretation were still being actively challenged long after his death. Some scientists supported his conclusions, others did not. Wilder Penfield was the first prominent investigator to uphold Hortega. He described, in the first issue of the American Journal of Pathology, the various stages of microglia, going from resting to reactive (Penfield, 1925). Numerous others did differing experiments, interpreting microglia cells as being of epithelial origin with unknown function. A detailed account of the continuing controversy, which extended for over six decades, appears in Haymaker and Adams (1980b, Chapter VI). This unjustified controversy may help to explain why Hortega never received a Nobel prize for his epic work.

The next giant step was taken by Ralph van Furth. He elaborated the concept of a monocyte phagocytic system to explain the origin and function of resident phagocytes throughout the body. The Memoranda endorsing the concept, which was introduced at the Conference on Mononuclear Phagocytes held in Lieden in 1969, is available on the web Chttp://www.ncbi.nlm. nih.gov/pmc/articles/PMC2480884/pdf/bullwho00193-0157.pdf. $\mathrm{He}$ and his colleagues had studied labeled monocytes and their marrow precursors and followed their appearance as typical macrophages in various organs, including brain (Van Furth and Cohn, 1968). This concept replaced the vague theory of a reticuloendothelial system introduced by Aschoff (1924) which, despite its shortcomings, had become entrenched in medical teaching.

While van Furth's concept of a monocyte phagocytic system was widely accepted, its relationship to brain microglia was not. 
Fujita in particular opposed the idea that microglia were the brain representatives of this system. He injected tritiated thymidine into chick embryos and identified labeled brain cells which he interpreted as glioblasts of subependymal origin (Fujita, 1965). He did later studies of human embryonic brain tissue and reached a similar conclusion, that brain microglia were of epithelial and not mesenchymal origin (Fujita, 1973; Fujita and Kitamura, 1973).

Oemichan et al. (1979) and Wood et al. (1979) also concluded that brain microglia could not be phagocytes of monocytic origin. The reason was that they could not detect the same surface antigens on microglial cells that they were able to detect on peripheral monocytes. The idea became established that inflammation of the brain did not involve microglia, and did not occur unless there was invasion of the brain by peripheral monocytes, which then became transformed into macrophages.

\section{IDENTIFICATION OF HLA-DR POSITIVE MICROGLIA IN HUMAN BRAIN}

The entry of our laboratory into the neuroinflammatory field was entirely serendipitous. Several researchers had suggested that AD might result from a herpes infection entering through the nasal passages because of involvement of the rhinencephalon (Ball, 1982). Our effort over some years to detect herpes virus in the CNS had failed, although we were able to detect it in some cases in the trigeminal nucleus, the source of herpes labialis (Walker et al., 1989). We sought the advice of local immunologists regarding what might be a broader indicator of a viral infection, and were counseled to look for HLA-DR since this class II glycoprotein would be responsible for presenting viral epitopes to T-cells. We were even presented with a gift of the HB-104 cell line, known to produce high levels of antibodies against HLA-DR.

The results astonished us. A plethora of cells was visible in $\mathrm{AD}$ tissue with a morphology that was completely unfamiliar to us. However we were able to confirm that they were microglia by showing them to the founder of our laboratory, Dr. William Gibson, who had been a student and biographer of Hortega (Prados and Gibson, 1946). The morphology was identical to that published by Del Rio Hortega (1919), permitting us to sense in a very small way the excitement he must have experienced.

As many frustrated investigators well know, peer reviewers, whether evaluating applications for research grants, or papers submitted to journals, are typically well versed in the dogmas of the day. Findings that radically conflict with established views are too often dismissed. Our data conflicted with two dogmas. The first was that microglia were of epithelial origin and were not immunocompetent cells. The second was that brain inflammation was not a characteristic of AD. A pathological journal rejected our initial manuscript, reasoning that the absence of a neuropathologist as an author explained the faulty conclusions. A peer reviewer for a renewal of our grant dismissed it with the comment "the hypothesis is ridiculous." Nevertheless, our first paper appeared as a brief report in Neuroscience Letters (McGeer et al., 1987).

This final validation of Hortega depended on the availability of HB-104, a powerful and highly specific monoclonal antibody. The field of immunohistochemistry had been opened by Cesar Milstein's work on the technique for producing monoclonal antibodies. He was a co-winner of the Nobel prize in 1984 for this accomplishment. Then, as now, the ability to visualize brain biochemistry through the eyes of immunohistochemistry depends on the strength and specificity of the antibodies employed. HB104 was a particularly good antibody, permitting us to make a clear distinction, which had eluded other investigators, between HLA-DR positive microglia and GFAP positive astrocytes.

We were not the first to report class II staining of brain cells. Lampson and Hickey (1986) had reported class II activity in occasional cell bodies of human brain with the "morphologic appearance of microglia or astrocytes." Similarly deTribolet et al. (1984) reported HLA-DR positive cells in the white matter of normal brain which they interpreted as being astrocytes (deTribolet et al., 1984). Rogers et al. reported HLA-DR positive microglia and astrocytes in $\mathrm{AD}$ in an abstract at the Society of Neuroscience meeting in 1986 but, as in our case, formal publication was held up by disbelief in the findings. Their work finally appeared in 1988 (Luber-Narod and Rogers, 1988; Rogers et al., 1988).

These data led to a number of unanswered questions. What was the source of the inflammation in $\mathrm{AD}$ ? Was it a special phenomenon or a general one that applied to many chronic neurological disorders? If it was a general phenomenon, was it localized to the brain or did it involve the peripheral immune system? Was it helpful or harmful to ongoing degenerative processes? What were the implications for treatment? Exploration of these questions led to the opening up of an important new field of neuroscience, namely neuroinflammation.

\section{ESTABLISHMENT OF NEUROINFLAMMATION AS A DISTINCT FIELD OF NEUROSCIENCE RESEARCH}

The question as to whether or not the presence of activated microglia in brain was a special one applying to $\mathrm{AD}$, or a general phenomenon was quickly answered. HLA-DR activated microglia were observed in a variety of degenerative neurological conditions, including Parkinson disease (PD), Pick disease, ALS, Huntington disease, multiple sclerosis, AIDS encephalopathy, parkinsonism dementia of Guam, and the Shy-Drager syndrome (McGeer et al., 1988a). Their phagocytic function was easily demonstrated by melanin being observed within the HLA-DR positive microglia of the SN (McGeer et al., 1988b). Each of these diseases has a differing etiology, so the activated microglial response had to be the consequence of initiating factors in each condition and not the fundamental cause.

At this same time, the laboratory of Kreutzberg in Germany was carrying out work of a more fundamental nature. His team was utilizing the facial nerve axotomy model to examine the CNS reaction to a sterile lesion outside of the CNS. They found activated microglia enveloping damaged neurons of facial nerve cell bodies, with phagocytosis of dead cells taking place. They concluded that microglia might function as antigen presenting cells and thus be the effector cells responsible for recruitment of lymphocytes to the brain resulting in an inflammatory reaction. A review of their results appeared in the first volume of Glia (Streit et al., 1988) and a later review (Kreutzberg, 1996).

Further groundwork was laid by four key papers which appeared in a special issue of Glia in 1993 devoted to microglia. They were by Ling and Wong (1993) describing the origin and nature of microglia; Dickson et al. (1993) detailing cytokines and microglia in Alzheimer disease and AIDS; Banati et al. (1993) 
on the cytotoxicity of microglia; and McGeer et al. (1993) on microglia in neurodegenerative diseases generally.

Since our laboratory and that of Joe Rogers, who had founded the Sun Health Research Institute, had identified HLA-DR activated microglia in $\mathrm{AD}$, we joined forces for further investigation of the phenomenon, particularly the role of complement. The name complement was introduced by Paul Ehrlich in the 1890's to explain the heat labile factor in serum which helped antibodies to kill microorganisms. As a result, complement was considered to be a peripherally generated system for assisting the activity of antibodies. It was therefore believed that complement factors would only be found as an accompaniment to immunoglobulin antibodies.

Eikelenboom and Stam (1982) were the first to report the presence of complement factors in AD senile plaques. Previously it had been reported that immunoglobulins were associated with amyloid deposits, which was consistent with prevailing theory (Ishii and Haga, 1975). Our laboratory was able to detect the opsonizing components of the classical complement pathway in association with plaques, and the membrane attack complex in association with dystrophic neurites, consistent with bystander lysis occurring in $\mathrm{AD}$ (McGeer et al., 1989).

Working with Joseph Rogers, we were unable to detect immunoglobulins in AD tissue using a host of antibodies. Then Rogers explored the idea that beta amyloid protein itself might be an activator of complement. In a classic paper he and his colleagues demonstrated that immunoglobulin immunostaining did not colocalize with complement, and that beta amyloid protein and its N-terminal fragments bound to C1q directly, thus initiating the complement cascade independently of antibodies (Rogers et al., 1992). But what was the source of the complement proteins? It was soon determined from RNA studies that brain itself was the source (Johnson et al., 1992; Walker and McGeer, 1992). Meanwhile evolutionary studies were underway, establishing that the complement system could be traced back at least as far as horseshoe crabs and that it was the mainstay of innate immunity in most primitive organisms (Zhu et al., 2005). It far predated the antibody producing adaptive immune system which is an invention of higher vertebrates.

Two principles which had broad implications for the developing field of neuroinflammation emerged from this joint endeavor. The first was establishing that complement was part of the innate immune system and further that it had the potential of exacerbating the pathology through formation of the membrane attack complex. The second was showing that the inflammatory reaction in AD did exacerbate the pathology. We decided to explore whether patients on long term anti-inflammatory therapy were relatively spared from $\mathrm{AD}$. We selected rheumatoid arthritic patients because onset of the disease typically appears at an earlier age than $\mathrm{AD}$ and involves aggressive anti-inflammatory therapy. The results showed an estimated sixfold sparing of AD in rheumatoid arthritic patients compared with age matched general populations (McGeer et al., 1990). Many subsequent epidemiological studies, in which consumption of NSAIDs in particular were targeted, confirmed these general findings (McGeer and McGeer, 1995).

Rogers was then motivated to establish a Neuroinflammation Working Group of 37 investigators to assemble the rapidly accumulating data on inflammation in $\mathrm{AD}$. The conclusion of the group was that the data represented "a virtual textbook of inflammatory mediators." Included were complement proteins and their regulators, inflammatory cytokines, chemokines, acute phase reactants, prostaglandins, proteases, protease inhibitors, coagulation factors, fibrinolytic factors, integrins, anaphylatoxins, free radical generators, and other unidentified neurotoxins (Akiyama et al., 2000). All are products of the innate immune system of brain, with major contributions coming from neurons, astrocytes, microglia, and endothelial cells.

Parkinson disease was another chronic degenerative disorder where activated microglia were detected in association with the SN lesions (McGeer et al., 1988b). An accidental model of PD provided new insights into the consequences of chronic neuroinflammation. Langston et al. (1984) had identified a group of young drug users who suddenly developed a parkinsonian syndrome. The causative agent $(\mathrm{MPP}+)$ was a metabolite of 1-methyl-4phenyl-1,2,3,6-tetrahydropyridine (MPTP), a contaminant in the street drug they were using. The condition was progressive, and autopsy studies on those who had died from this exposure years previously showed neuroinflammation of the SN similar to that observed in PD (Langston et al., 1999). We found a parallel situation in monkeys. They showed nigral degeneration and activated microglia in the SN 5.5-15 years after systemic exposure to MPTP (McGeer et al., 2003). These findings represent the clearest example of how neuroinflammation, once initiated, can persist, and cause continuing neurodegeneration.

Activated microglia are the pivotal cells. Their functioning in vivo has been remarkably demonstrated by the movies of Nimmerjahn et al. (2005). They developed mice transgenic for a green fluorescent protein in microglial cells and used two-photon microscopy through a window in the skull to observe their behavior. Microglial cells in the normal state were found not to be dormant, as implied by their traditional designation as resting, but were extremely active, continuously extending, and retracting their processes to sense their environment. When activated by a laser lesion of a capillary, they surrounded the lesion and phagocytosed the leaking blood.

The innate immune system is the body's first line of defense. As the Nimmerjahn movies demonstrate, it can act immediately. As shown in chronic degenerative diseases, as well as the MPTP model, it can maintain its activity indefinitely without significant engagement of the adaptive immune system. The adaptive immune system is slower to react but more powerful and specific in attacking targets. It depends upon appropriate presentation of epitopes to lymphatic organs so that lymphocytes can be cloned to attack targets where that epitope is exposed. There is a long list of diseases where the adaptive immune system directs self attack on healthy tissues. These conditions are known as autoimmune disorders. They differ from $\mathrm{AD}$ and other chronic neurodegenerative disorders where the adaptive immune system does not become significantly engaged. To distinguish between the two, we have suggested that such diseases be described as autotoxic disorders (McGeer and McGeer, 2000).

In theory, the self destruction in autotoxic disorders should be milder and more amenable to therapeutic intervention than the self destruction in autoimmune disorders. The question is how to 
ameliorate the autotoxic response? Anti-inflammatory and antioxidant approaches have been the most widely utilized to date. But another, and potentially more effective method may be possible. That is to transform microglia from the attack mode, which has been so well characterized, to a healing mode. Such a transformation might result in enhanced phagocytotic activity, coupled with a switch from expressing inflammatory cytokines such as IL-1 and TNF to expressing anti-inflammatory cytokines such as IL-4 and IL-10. In the process the beneficial effects of phagocytosis might be enhanced. For example, suppressing the CD-40/CD 40L interaction in transgenic mice enhances the phagocytic activity of microglia and increase $A \beta$ clearance (Tan et al., 2002). Clearly there is much still to be learned. It can be said that, despite the huge expansion of activity that has taken place in recent years, it is still a field in its infancy.

\section{SUMMARY}

Our understanding of the innate immune system in brain commenced with recognition of a single marker, HLA-DR, on a single cell type, microglia, in a single disorder, Alzheimer disease. Twenty

\section{REFERENCES}

Akiyama, H. Barger, S., Barnum, S., Bradt, B., Bauer, J., Cole, G. M., Cooper, N. R., Eikelenboom, P., Emmerling, M., Fiebich, B. L., Finch, C. E., Frautschy, S., Griffin, W. S., Hampel, H., Hull, M., Landreth, G., Lue, L., Mrak, R., Mackenzie, I. R., McGeer, P. L., O’Banion, M. K., Pachter, J., Pasinetti, G., Plata-Salaman, C., Rogers, J., Rydel, R., Shen, Y., Streit, W., Strohmeyer, R., Tooyoma, I., Van Muiswinkel, F. L., Veerhuis, R., Walker, D., Webster, S., Wegrzyniak, B., Wenk, G., Wyss-Coray, T, and Neuroinflammation Working Group. (2000). Inflammation and Alzheimer's disease. Neurobiol. Aging 21, 383-421.

Aschoff, L. (1924). Das reticuloendotheliale system. Ergeb. Inn. Med. Kinderheilkd. 26, 1.

Ball, M. J. (1982). Limbic predilection in Alzheimer dementia: is reactivated herpes virus involved. Can. J. Neurol. Sci. 9, 303-306.

Banati, R. B., Gehrmann, J., Schubert, P., and Kreutzberg, G. W. (1993). Cytotoxicity of microglia. Glia 7 , 111-118.

Del Rio Hortega, P. (1919). El tercer elemento de los centros nerviosis. Bol. Soc. Esp. Biol. 9, 69-129.

deTribolet, N., Hamou, M. F., Mach, J.-P., Carrel, S., and Schreyer, M. (1984). Demonstration of HLA-DR antigens in normal human brain. J. Neurol. Neurosurg. Psychiatr. 47, 417-418.

Dickson, D. W., Lee, S. C., Mattiace, L. A.,Yen, S. H. C., and Brosnan, C. (1993). Microglia and cytokines in neurological disease, with special reference to AIDS and Alzheimer's disease. Glia 7, 75-83.

Eikelenboom, P., and Stam, F. C. (1982). Immunoglobulins and complement factors in senile plaques. Acta $\mathrm{Neu}$ ropathol. 57, 239-242.

Fujita, S. (1965). An autoradiographic study on the origin and fate of the sub-pial glioblast in the embryonic chick spinal cord. J. Comp. Neurol. 124, 51-59.

Fujita, S. (1973). Genesis of glioblasts in the human spinal cord as revealed by Feulgen cytophotometry. J. Comp. Neurol. 151, 25

Fujita, S., and Kitamura, T. (1973). Origin of brain macrophages and the nature of so-called microglia. Acta Neuropathol. Suppl. 6, 291-296.

Haymaker, W., and Adams, R. D. (1980a). Histology and Histopathology of the Nervous System. Springfield, IL: C. C. Thomas, 484-485.

Haymaker, W., and Adams, R. D. (1980b). Histology and Histopathology of the Nervous System, Chapter VI. Springfield, IL: C. C. Thomas, 481-559.

Ishii, T., and Haga, S. (1975). Identificantion of components of immunoglobulins in senile plaques by means of fluorescent antibody technique. Acta Neuropathol. 32, 157-162.

Johnson, S. A., Lampert-Etchells, M., Pasinetti, G. M., Rozovsky, I., and Finch, C. E. (1992). Complement mRNA in the mammalian brain: responses to Alzheimer's disease and experimental brain lesioning. $\mathrm{Neu}$ robiol. Aging 13, 641-648.

Kreutzberg, G. W. (1996). Microglia: a sensor for pathological events in the CNS. Trends Neurosci. 19, 312-318.

five years later, more than a thousand innate immune system markers have been identified which are associated with neurons, astrocytes, oligodendrocytes, and endothelial cells, as well as microglia.

They include, but are not limited to, complement proteins and their regulators, cytokines, chemokines, acute phase reactants, prostaglandins, proteases, protease inhibitors, coagulation factors, fibrinolytic factors, anaphylatoxins, integrins, and free radical generators. They are found in a spectrum of neurological diseases. Some stimulate inflammation, others inhibit it. Shifting the balance from a mode of attack to one of healing holds promise of having significant therapeutic benefit in a spectrum of degenerative diseases. Clearly there is much still to be learned. It can be said that, despite the huge expansion of activity that has taken place in the last 25 years, it is still a field in its infancy.

\section{ACKNOWLEDGMENTS}

This work was supported by the Pacific Alzheimer Research Foundation.

Lampson, L. A., and Hickey, W. F. (1986). Monoclonal antibody analysis of MHC expression in human brain biopsies: tissue ranging from "histologically normal" to that showing different levels of glial tumor involvement. J. Immunol. 136, 4054-4062.

Langston, J. W., Forno, L. S., and Tetrud, J., Reeves, A. G., Kaplan, J. A., and Karluk, D. (1999). Evidence of active nerve cell degeneration in the substantia nigra of humans years after 1-methyl-4-phenyl-1,2,3,6tetrahydropyridine exposure. Ann. Neurol. 46, 598-605.

Langston, J. W., Irwin, I., Langston, E. B., and Forno, L. S. (1984). 1-Metyl-4phenylpyridium ion $(\mathrm{MPP}+)$ : identification of a metabolite of MPTP, a toxin selective to the substantia nigra. Neurosci. Lett. 48 87-92.

Ling, E. A., and Wong, W. C. (1993) The origin and nature of ramified and ameboid microglia - a historical review and current concepts. Glia 7 , 9-18.

Luber-Narod, J., and Rogers, J. (1988). Immune system associated antigens expressed by cells of the human central nervous system. Neurosci. Lett. 94, 17-22.

McGeer, P. L., Akiyama, H., Itagaki, S., and McGeer, E. (1989). Activation of the classical complement pathway in brain tissue of Alzheimer patients. Neurosci. Lett. 107, 341-346.

McGeer, P. L., Itagaki, S., and McGeer, E. G. (1988a). Expression of the histocompatibility glycoprotein HLA-DR in neurological disease. Acta Neuropathol. 76, 550-557.
McGeer, P. L., Itagaki, S., Akiyama, H., and McGeer, E. G. (1988b). Rate of cell death in parkinsonism indicates active neuropathological process. Ann. Neurol. 24, 574-576.

McGeer, P. L., Itagaki, S., Tago, H., and McGeer, E. G. (1987). Reactive microglia in patients with senile dementia of the Alzheimer types are positive for the histocompatibility glycoprotein HLA-DR. Neurosci. Lett. 79, 195-200.

McGeer, P. L., Kawamata, T, Walker, D. G., Akiyama, H, Tooyama, I. and McGeer, E. G. (1993). Microglia in degenerative neurological disease. Glia 7, 84-92.

McGeer, P. L., and McGeer, E. G. (1995). The inflammatory response system of brain: implications for therapy of Alzheimer and other neurodegenerative disorders. Brain Res. Rev. 21, 195-218.

McGeer, P. L., and McGeer, E. G. (2000). Autotoxicity and Alzheimer disease. Arch. Neurol. 57, 789-790.

McGeer, P. L., Rogers, J., McGeer, E. G., and Sibley, J. (1990). Does anti-inflammatory treatment protect against Alzheimer disease? Lancet 335, 1037.

McGeer, P. L., Schwab, C., Parent, A., and Doudet, D. (2003). Presence of reactive microglia in monkey substantia nigra years after 1-methyl-4phenyl-1,2,3,6-tetrahydropyridine administration. Ann. Neurol. 54, 599-604.

Nimmerjahn, A., Kirchhoff, F., and Helmchen, F. (2005). Resting microglial cells are highly dynamic surveillants of brain parenchyma in vivo. Science 308, 1314-1318 
Oemichan, M., Wietholter, H., and Greaves, M. F. (1979). Immunoloical analysis of human microglia: lack of monocytic and lymphoid membrane differentiation antigens. J. Neuropath. Exp. Neurol. 38, 99-103.

Penfield, W. (1925). Microglia and the process of phagocytosis in gliomas. Am. J. Pathol. 1, 77-89.

Prados, M., and Gibson, W. C. (1946). Pio del Rio Hortega, 1882-1945. J. Neurosurg. 3, 275-284.

Rogers, J., Cooper, N. R., Webster, S., Schultz, J., McGeer, P. L., Styren, S. D., Civin, W. H., Brachova, L., Bradt, B., Ward, P., and Lieberburg, I. (1992). Complement activation by $\beta$-amyloid in Alzheimer disease. Proc. Natl. Acad. Sci. U.S.A. 89, 10016-10020.

Rogers, J., Luber-Narod, J., Sturen, C. D., and Civin, W. H. (1988). Expression of immune system-associated antigens by cells of the human central nervous system: relationship to the pathology of Alzheimer's disease. Neurobiol. Aging 9, 339-349.

Streit, W. J., Graeber, M. B., and Kreutzberg, G. W. (1988). Functional plasticity of microglia: a review. Glia 1, 301-307.

Tan, J., Town, T., Crawford, F., Mori, T., DelleDonne, A., Crescentini, R., Obregan, D., Flavelli, R. A., and Mullan, M. J. (2002). Role of CD40 ligand in amyloidosis in transgenic Alzeheimer's mice. Nat. Neurosci. 5, 1288-1293.

Van Furth, R., and Cohn, Z. A. (1968). The origin and kinetics of mononuclear phagocytes. J. Exp. Med. 128, 415-435.

Walker, D. G., and McGeer, P. L. (1992). Complement gene expression in human brains: comparison between normal and Alzheimer disease cases. Brain Res. Mol. Brain Res. 14, 109-116.

Walker, D. G., O'Kusky, J. R., and McGeer, P. L. (1989). In situ hybridization analysis for herpes simplex virus nucleic acids in Alzheimer disease. Alzheimer Dis. Assoc. Disord. 3, 123-131.

Wood, G. W., Gollahon, K. A., Tilzer, S. A., Vats, T., and Morantz, R. A. (1979). The failure of microglia in normal brain to exhibit mononuclear phagocyte markers. J. Neuropathol. Exp. Neurol. 38, 369-376.

Zhu, Y., Thangamani, S., and Ho, B. And Ding, J. L. (2005). The ancient origin of the complement system. EMBO J. 24, 382-394.

Conflict of Interest Statement: The authors declare that the research was conducted in the absence of any commercial or financial relationships that could be construed as a potentia conflict of interest.

Received: 24 October 2011; accepted: 14 November 2011; published online: 02 December 2011.

Citation: McGeer PL and McGeer EG (2011) History of innate immunity in neurodegenerative disorders. Front. Pharmacol. 2:77. doi: 10.3389/fphar.2011.00077

This article was submitted to Frontiers in Neuropharmacology, a specialty of Frontiers in Pharmacology.

Copyright (C) 2011 McGeer and McGeer. This is an open-access article distributed under the terms of the Creative Commons Attribution Non Commercial License, which permits non-commercial use, distribution, and reproduction in other forums, provided the original authors and source are credited. 